\title{
A Case Report of Post-traumatic Osteomyelitis with Gap Non-union of Humerus with Segmental Bone Defect and Scarred Skin Treated with Open Reduction Internal Fixation with Osteomyocutaneous Fibula
}

\author{
Prakash K. George ${ }^{1}$, Bibhas Dasgupta ${ }^{1}$, Bhanuprakash Reddy ${ }^{1}$, P. V. Shubhanshu Bhaladhare ${ }^{1}$
}

Learning Point of the Article:

Osteomyocutaneous fibula flap provides a valuable treatment options in complicated humerus nonunion cases allowing for both bone union and soft-tissue coverage with a single surgical procedure.

\section{Abstract}

Introduction: Non-union of closed humerus fractures is estimated to be about $5.5 \%$ and this figure is even higher in open fractures. In cases of non-union of the humerus with segmental bone defect, if a conventional treatment has failed, free fibular transfer is often considered for satisfactory bone union. In some cases, where there is severe scarring due to multiple previous surgeries. In such cases, skin cover may not be adequate and tight closures often lead to necrosis and failure excision. Segmental bone defects of the upper limb that is $>6 \mathrm{~cm}$ with soft-tissue coverage defects have limited options for reconstruction. Osteomyocutaneous fibula may provide to be a valuable option in such cases.

Case Report: This is a report a case of a 27-year-old male presented with a history of road traffic accident with Gustilo-Anderson Grade $3 \mathrm{~B}$ open fracture of humerus midshaft. He developed humerus osteomyelitis, for which he underwent surgical debridement. He presented to us with gap non-union with segmental bone loss. The overlying skin was scarred and had significant limb shortening. Treatment options for such a case are reconstruction or amputation. Challenges for reconstruction were to deal with the segmental bone loss and the soft-tissue defect following scar excision. We tackled both these challenges with an osteomyocutaneous fibula flap. At 1-year follow-up, the humerus showed union and flap uptake was good.

Conclusion: Osteomyocutaneous fibula flap is a valuable treatment options in such complicated cases allowing for both bone union and softtissue coverage with a single surgical procedure.

Keywords: Osteomyocutaneous flap, humerus gap nonunion, osteomyelitis humerus.

\section{Introduction}

Non-union of closed humerus fractures is estimated to be about $5.5 \%$ and this figure is even higher in open fractures. In cases of non-union of the humerus with segmental bone defect, if a conventional treatment has failed, free fibular transfer is often considered for satisfactory bone union. In some cases, where there is severe scarring due to multiple previous surgeries. In such cases, skin cover may not be adequate and tight closures often lead to necrosis and failure excision. Segmental bone defects of the upper limb that is $>6 \mathrm{~cm}$ with soft-tissue coverage defects have limited options for reconstruction. Surgical options for the treatment of humerus non-union include nailing, use of Ilizarov technique, and compression plates with non-vascularized bone graft and vascularized bone grafts and osteomyocutaneous fibula flap [2-5]. Osteomyocutaneous fibula may provide to be a valuable option in such cases.

\section{Case Report}

A 27-year-old male had a history of road traffic accident with Grade 3 B (As per Gustilo-Anderson classification) [6] open fracture of humerus midshaft. The patient underwent debridement and external fixator application at some other

Author's Photo Gallery

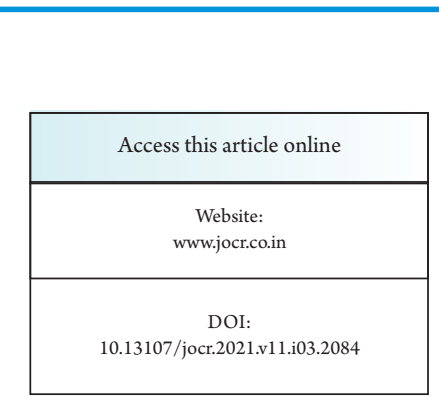

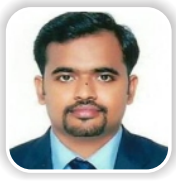

Dr. Prakash K. George

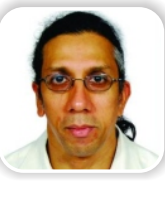

Dr. Bibhas Dasgupta

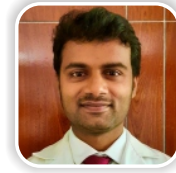

Dr. Bhanuprakash Reddy

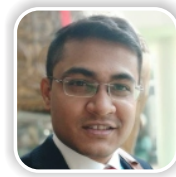

Dr. P. v. Shubhanshu Bhaladhare
'Department of Orthopedics, Seth G. S. Medical College and KEM Hospital, Parel, Mumbai, Maharashtra, India.

Address of Correspondence:

Dr. Prakash K. George,

Department of Orthopedics, Seth G. S. Medical College and KEM Hospital, Parel, Mumbai, Maharashtra, India.

E-mail: drprakashkgeorge@gmail.com

Journal of Orthopaedic Case Reports | pISSN 2250-0685 | eISSN 2321-3817 | Available on www.jocr.co.in | doi:10.13107/jocr.2021.v11.i03.2084 This is an Open Access article distributed under the terms of the Creative Commons Attribution Non-Commercial License (http://creativecommons.org/licenses/by-nc/3.0) which permits unrestricted non-commercial use, distribution, and reproduction in any medium, provided the original work is properly cited. 


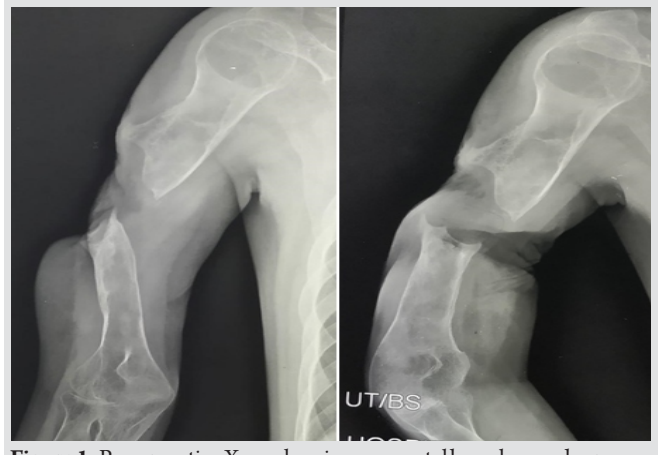

Figure 1: Pre-operative X-ray showing segmental bone loss and gap nonunion of humerus shaft.
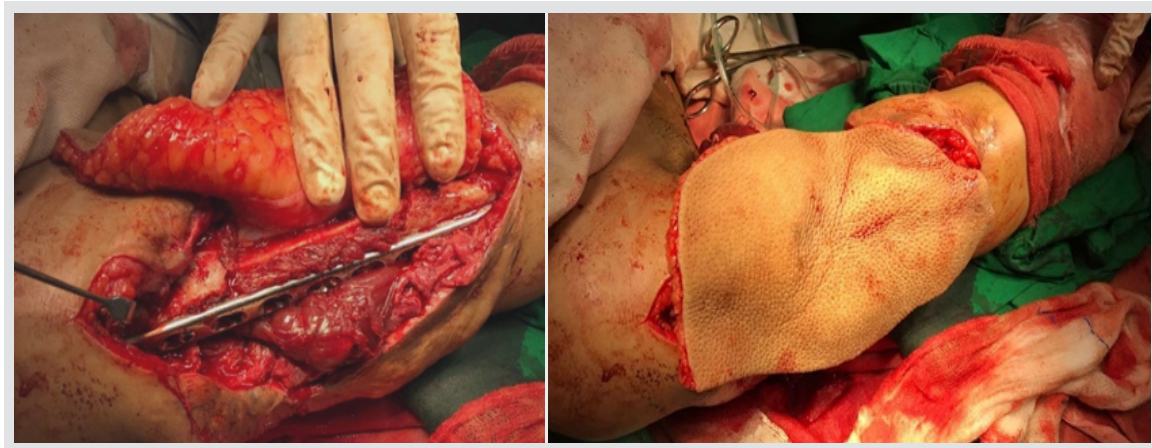

Figure 2: Intraoperative picture showing osteomyocutaneous fibula and plate in situ and skin coverage achieved.

hospital, later wound healed but the bone ends became osteomyelitic. Debridement was done for the same in the same hospital, the patient presented to us with segmental bone loss (7 $\mathrm{cm}$ ) and gap nonunion. The skin overlying was scarred and there was limb shortening (Fig. 1).

Surgical technique involved approach of both upper and lower limbs simultaneously, with the patient in the supine position. The humeral approach was based on the previous incisions and soft-tissue defects. For non-union, necrotic bone was resected and debridement done, the ends were reamed sequentially to open the canal and to allow the fibula to go inside the humerus medullary cavity. The brachial vessels were identified for anastomosis. The osteomyocutaneous fibular graft was based on the peroneal vessels. The harvested flap included skin paddle, fibula, skin perforators (majority present on the inferomedial part of the fibula), and the peroneal vessels with the venae comitantes.

A length of $16 \mathrm{~cm}$ and a width of $12 \mathrm{~cm}$ of skin flap were harvested along with $9.5 \mathrm{~cm}$ of fibula bone.

The graft was inserted $2 \mathrm{~cm}$ at each end into the humerus, and then, the entire construct was fixed with a $4.5 \mathrm{~mm}$ low contact dynamic compression plate with two screws on either side getting four cortex purchase. The peroneal artery was anastomosed end-to-side with the brachial artery. The skin margins of the flap were fashioned accordingly and were sutured

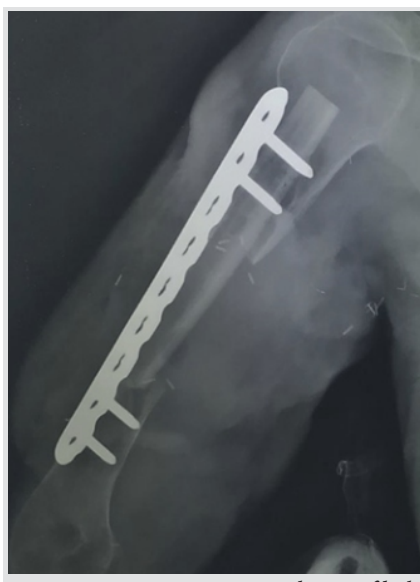

Figure 3: Post-operative X-ray showing fibula graft fixed with plates and screws.

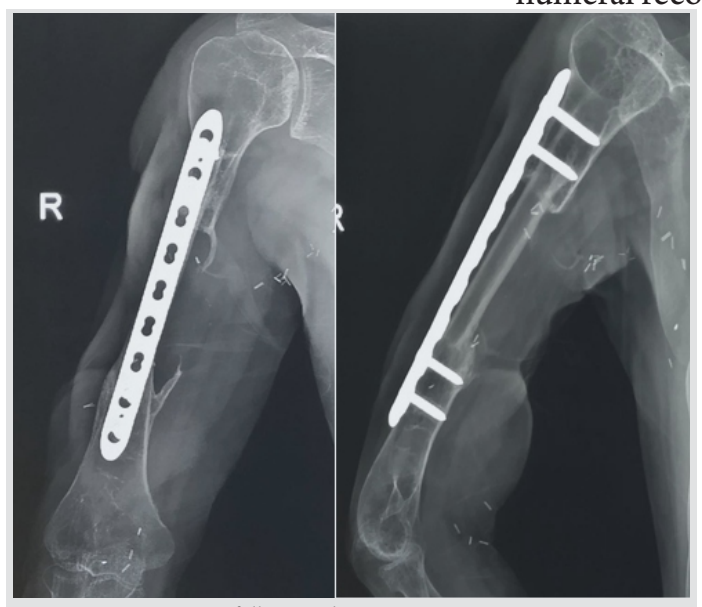

Figure 4: X-ray at 1-year follow-up showing union. to the surrounding skin (Fig. 2,3).

Postoperatively, flap was closely monitored for vascularity and viability and the fixation was protected by a $U$ slab, which was later converted into a functional humerus brace. Physiotherapy started with range of motion and followed by muscle strengthening. Serial X-rays were taken to assess bone union at 6 months and 1 year (Fig. 4, 5).

\section{Discussion}

Segmental bone defects of the upper limb that is $>6 \mathrm{~cm}$ with soft-tissue coverage defects have limited options for reconstruction $[7,8]$. Osteomyocutaneous fibula flap provides a valuable treatment option for the problems with a single surgical procedure allowing for both bone union and soft-tissue coverage.

A vascularized bone graft does not resorb it can increase its structural strength by hypertrophy. The healing of the vascularized bone graft is comparable to acute fracture healing in contrast to process of creeping substitution of a nonvascularized allograft

Wright et al. [9] used an intramedullary fibular bone graft and a compression plate in nine humeral non-unions. Eight of the nine fractures united at an average of 3.5 months.

In a study, Wood et al. [10] reported on 11 patients who had a humeral reconstruction with a vascularized fibular graft. Seven

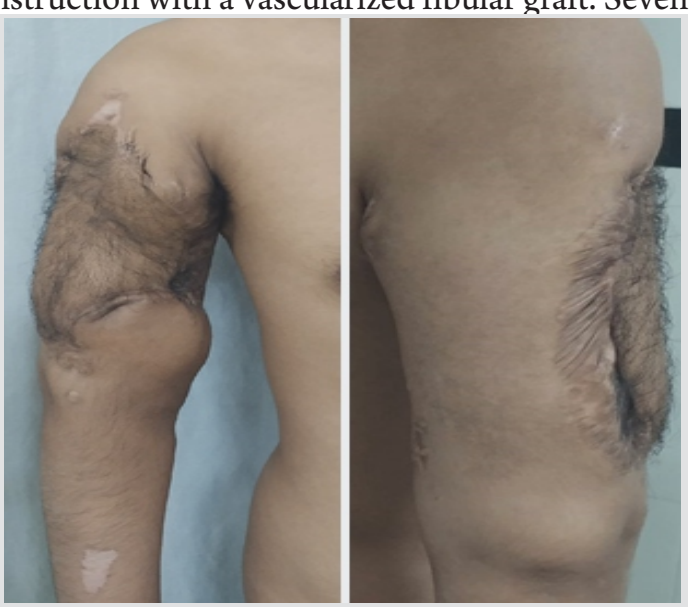

Figure 5: Clinical picture at 1-year follow-up. 
of the 11 patients had resection of a tumor, and the remaining four patients had nonunion. Five of the 11 patients had development of a non-union at the site of the reconstruction. Despite the associated complications, the use of a vascularized fibula is a valuable option in these difficult salvage situations when one considers the alternatives, such as above-the-elbow amputation.

\section{Conclusion}

Osteomyocutaneous fibula flap provides a valuable treatment option for segmental bone defects of more than $6 \mathrm{~cm}$ associated with soft-tissue defects with a single surgical procedure allowing for both bone union and soft-tissue coverage.

Thus, osteomyocutaneous flap can be used as a versatile tool in many situations such as trauma, tumor resections, and osteomyelitis.

\section{Clinical Message}

Osteomyocutaneous fibula flap provides a valuable treatment option for segmental bone defects of more than $6 \mathrm{~cm}$ associated with soft-tissue defects with a single surgical procedure allowing for both bone union and soft-tissue coverage.

\section{References}

1. Volgas DA, Stannard JP, Alonso JE. Nonunions of the humerus. Clin Orthop 2004;419:46-50.

2. Tang CH. Reconstruction of the bones and joints of the upper extremity by vascularized free fibular graft: Report of 46 cases. J Reconstr Microsurg 1992;8:285-92.

3. Tu YK, Yen CY, Yeh WL, Wang IC, Wang KC, Ueng SW. Reconstruction of posttraumatic long bone defect with free vascularized bone graft: Good outcome in 48 patients with 6 years' follow-up. Acta Orthop Scand 2001;72:35964.

4. Yajima H, Tamai S, Ono H, Kizaki K, Yamauchi T. Free vascularized fibula grafts in surgery of the upper limb. J Reconstr Microsurg 1999; 15:515-21.

5. Minami A, Kasashima T, Iwasaki N, Kato H, Kaneda K. Vascularised fibular grafts. An experience of 102 patients. J Bone Joint Surg Br 2000;82:1022-5.

6. Gustilo RB, Anderson JT. Prevention of infection in the treatment of one thousand and twenty-five open fractures of long bones: Retrospective and prospective analyses. J Bone Joint Surg Am 1976;58:453-8.

7. Wright TW, Miller GJ, Griend RA, Wheeler D, Dell PC. Reconstruction of the humerus with an intramedullary fibular graft. A clinical and biomechanical study. J Bone Joint Surg Br 1993;75:804-7.

8. Jupiter JB. Complex non-union of the humeral diaphysis. Treatment with a medial approach, an anterior plate, and a vascularized fibular graft. J Bone Joint Surg Am 1990;72:701-7.

9. Wright TW, Miller GJ, Griend RA, Wheeler D, Dell PC. Reconstruction of the humerus with an intramedullary fibular graft. A clinical and biomechanical study. J Bone Joint Surg Br 1993;75:804-7.

10. Wood MB. Upper extremity reconstruction by vascularized bone transfers: Results and complications. J Hand Surg Am 1987;12:422-7.

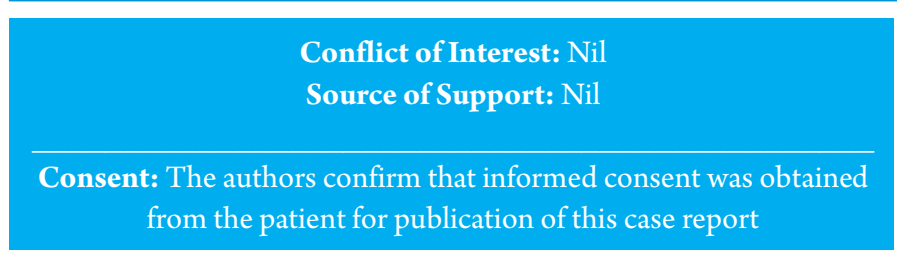

\section{How to Cite this Article}

George PK, Dasgupta B, Reddy B, Bhaladhare PVS. A Case Report of Posttraumatic Osteomyelitis with Gap Non-union of Humerus with Segmental Bone Defect and Scarred Skin Treated with Open Reduction Internal Fixation with Osteomyocutaneous Fibula. Journal of Orthopaedic Case Reports 2021 March;11(3): 52-54. 